\title{
PACT O EM DEFESA DA SAÚDE: divulgando os direitos dos usuários pela pesquisa-ação
}

\author{
M agda Santos KOERICHa \\ Dirce Stein BACKES \\ $M$ ara Caino M ARCHIORIC \\ Alacoque Lorenzini ERDM AN N ${ }^{d}$
}

\section{RESUM 0}

O bjetivou-se divulgar e discutir a Carta dos Direitos dos U suários do Sistema Ú nico de Saúde (SU S), com pacientes e familiares que buscaram atendimento em serviço público hospitalar. O ptou-se pela pesquisa-ação, com abordagem qualitativo-construtivista, que propõe a participação coletiva e ação planejada com ênfase na mudança de uma situação. A coleta de dados ocor reu concomitantemente às discussões com os usuários da saúde, no decorrer do ano de 2007, durante encontros semanais de aproximadamente uma hora. As falas codificadas e analisadas resultaram em três eixos temáticos: direitos e deveres dos usuários; qualificação profissional; acolhimento em saúde. Concluiu-se que a carta dos direitos dos usuários do SU S se coloca como um dispositivo importante para o cidadão conhecer os seus direitos de acesso ao sistema de saúde, bem como contribuir de forma critica e coresponsável nas discussões e delineamentos em prol de um sistema de saúde mais resolutivo e eficaz.

D escritores: Sistema Ú nico de Saúde. Direitos do paciente. Participação comunitária. Pesquisa em enfer magem.

\section{RESUMEN}

E I objetivo es divulgar y discutir la carta de los derechos de los usuarios del Sistema Ú nico de Salud (SU S), específicamente con los pacientes y los familiares que buscan atención en el servicio hospitalario. Se optó por la investigación-acción, con abordaje cual itativo- constructivista, que propone la participación y acción colectiva planificada con énfasis en los cambios de una situación. $L$ a recolección de la información ocurrió concomitantemente con las discusiones con los usuarios de salud, durante el año 2007, se llevaron a cabo encuentros semanales de a proximadamente una hora. L os cuales fuer on codificados y analizados en tres ejes temáticos: der echos y deberes de los usuarios; cualificación profesional; acogi mi ento en salud. L a carta delos derechos de los usuarios del SU S se pone como un dispositivo impor tante para que los ciudadanos conoz can sus derechos de acceso al sistema de sal ud, como contribuir deforma crítica y co-responsabl een las discusi ones y delineamientos en pro deun sistema de salud más resolutivo y eficaz.

D escriptores: Sistema Ú nico de Salud. D erechos del paciente Participación comunitaria. Investigación en enfermería. Título: Pacto en defensa de la salud: divulgando los derechos de los usuarios por la investigación-acción.

\footnotetext{
a D outora em Enfermagem, Professora do Departamento de Patologia da U niversidade Federal de Santa Catarina (UF SC), M embro do Grupo de Estudos e Pesquisas em Administração e G erência do Cuidado em Enfermagem e Saúde (GEPADES) do Programa de PósG raduação em Enfer magem (PEN) da U FSC, M embro do N úcleo de Estudos e Pesquisas sobre o Quotidiano e I maginário em Enfermagem e Saúde (N U PEQUIS-SC) do PEN da UFSC, Subcoordenadora do Comitê de Ética em Pesquisa com Seres Humanos da UFSC, F lorianópolis, Santa Catarina, Brasil.

${ }^{b}$ D outora em Enfermagem, Professora do Curso de Enfer magem do Centro U niversitário Franciscano (U NIF RA), M embro do GEPADES, Coordenadora do Grupo de Estudos e Pesquisas em Empreendedorismo Social em Enfermagem e Saúde (GE PESES), Santa M aria, Rio Grande do Sul, Brasil.

'M estre em E ducação, Professora do Curso de Enfermagem da U N IF RA, Pró-Reitora de Extensão da U N IF RA, Santa M aria, Rio G rande do Sul, Brasil.

- Doutora em Filosofia da Enfermagem, Professora Titular do Departamento de Enfermagem e do PEN da UFSC, Coordenadora do GEPADES, Coordenadora da Área da Enfermagem na Coordenação de A perfeiçoamento de Pessoal de Nível Superior (CAPES), PQ 1A do Conselho Nacional de Desenvolvimento Científico e Tecnológico (CN Pq), F lorianópolis, Santa Catarina, Brasil.
} 


\section{ABST RACT}

We objective to discuss the $U$ sers' R ights B ooklet of the $H$ ealth U nified System with patients and family members who had looked for attendance in public hospital service. 0 ne has chosen the action research, a qualitative and constructive method, which takes into account collective participation and planned action for changes of situations. The data w ere coll lected along with the research participants' discussions by means of weekly meetings throughout 2007. T hecodified speeches wereanalyz ed and resulted in threethemes: rights and duties of healthcare users; qualification of health professionals; receptivity to healthcare users. The users' rights booklet consists of an important means for citizens to know their rights of access to the healthcare system, allowing them to contribute in a critical and co-responsible way to discussions and actions in favor of a better healthcare system.

D escriptors: Single H ealth System. Patient rights. Consumer participation. N ursing research.

$T$ itle: D efense pact on health: discl osing the users' rights through action research.

\section{INT RODUÇÃO}

As discussões em torno do Sistema Ú nico de Saúde (SU S) são amplas e crescentes, envolvendo desde gestores, trabalhadores e a necessidade de articular a sociedade, usuários em geral, no intuito de construir políticas públicas mais efetivas e resolutivas.

Há mais de 10 anos emerge no Brasil um movimento pela humanização da atenção à saúde, a partir de produções acadêmicas, de necessidades identificadas pelos usuários e profissionais da saúde e da implantação em 2003, pelo M inistério da Saúde, do Programa $\mathrm{N}$ acional de H umanização da A tenção e G estão no SU S (H umaniza SU S) $)^{(1)}$. Ele reconhece que estados, municípios e serviços de saúde estão implantando práticas de humanização nas ações de atenção e gestão com bons resultados, contribuindo para a legitimação do SU S como política pública ${ }^{(2)}$.

A humanização da atenção à saúde ganhou novo enfoque, especificamente em três dimensões: o pacto pela vida, que considerou o compromisso sanitário, a priorização de necessidades de saúde da população principalmente dos grupos vulneráveis; o pacto em defesa do SU S, como um movimento de repolitização e mobilização da sociedade para a consolidação da política pública, que culminou na edição da Carta dos D ireitos dos U suários do SU S; o pacto de gestão, que busca a responsabilização solidária nas questões do planejamento, da programação pactuada e integrada, da regulamentação, participação e controle social além da gestão do trabal ho e educação na saúde ${ }^{(3,4)}$.

A Carta dos Direitos dos U suários do SU S se coloca como um dispositivo para o cidadão conhecer seus direitos de acesso ao sistema de saúde vigente e pretende estimular discussões nos diferen- tes níveis de atenção, capazes de ampliar a participação do usuário na cogestão e qualificação da atenção à saúde como um bem público.

A Carta é regida pelos seguintes princípios:

a) $1^{\circ}$ Princípio: todo cidadão tem direito ao acesso ordenado e organizado aos sistemas de saúde, isto é, acesso às ações e aos serviços de promoção, proteção e recuperação da saúde, promovidos pelo Sistema Ú nico de Saúde;

b) $2^{\circ}$ Princípio: todo cidadão tem direito a tratamento adequado e efetivo para seu problema. É direito dos cidadãos terem atendimento resolutivo com qualidade, em função da natureza do agravo, com garantia de continuidade da atenção, sempre que necessário;

c) $3^{\circ}$ P rincípio: todo cidadão tem direito ao atendimento humanizado, acolhedor e livre de qualquer discriminação. É direito dos cidadãos 0 atendimento acolhedor na rede de serviços de saúde de forma humanizada, livre de qualquer discriminação, restrição ou negação em função de idade, raça, cor, etnia, orientação sexual, identidade de gênero, características genéticas, condições econômicas ou sociais, estado de saúde, ser portador de patologia ou pessoa vivendo com deficiência;

d) $4^{\circ}$ Princípio: todo cidadão tem direito a atendimento que respeite a sua pessoa, seus valores e seus direitos;

e) $5^{\circ}$ P rincípio: todo cidadão também tem responsabilidades para que seu tratamento aconteça da forma adequada;

f) $6^{\circ}$ Princípio: todo cidadão tem direito ao comprometimento dos gestores da saúde para que os princípios anteriores sejam cumpridos ${ }^{(3)}$.

Dentre os princípios que norteiam o $\mathrm{H}$ umaniza-SU S, destacam-se a valorização da subjetividade; o fortalecimento dos direitos dos cidadãos; a 
construção de redes cooper ativas e solidárias com a produção da saúde e com os sujeitos; a autonomia, o protagonismo, a co-responsabilidade compartilhada entre os diferentes atores; o vínculo efetivo entre os difer entes sujeitos e a participação coletiva no processo de gestão(3,4).

A humanização é um processo complexo, demorado e amplo, que envolve mudanças de comportamento dos atores envolvidos e, por isso, com possibilidade de resistência da parte desses mesmos atores. É um processo singular, particular de cada instituição, que envolve conscientização e sensibilização, exigindo o empenho conjunto de usuários, trabalhadores, gover no e sociedade $e^{(5)}$.

N essa per spectiva, a humanização da atenção à saúde vem provocando o desenvolvimento de uma cultura de autonomia pela incorporação do diálogo dos diferentes saberes, a fim de que todos sejam autores e protagonistas do SU S, um dos maiores projetos públicos de inclusão social.

A humanização e direitos dos usuários também é tema de interesse das autoras e embasou muitas das discussões em seus grupos de pesquisa, surgindo então a idéia de desenvolver um estudo com o objetivo de divulgar e discutir a Carta dos Direitos dos U suários do SU S com pacientes e familiares que buscaram atendimento em serviço hospitalar.

\section{METODOLOGIA}

O ptou-se pela pesquisa ação, com abordagem qualitativo construtivista, que propõe a participação coletiva e ação planejada com ênfase na mudança de uma situaçãoo ${ }^{(6-8)}$. A coleta de dados ocorreu concomitantemente às discussões no decorrer do ano de 2007 durante encontros semanais com duração de uma hora.

Os participantes foram os usuários do SU S, convidados a participar das atividades de discussão e construção da proposta, por ocasião da procura de atendimento médico hospital ar em uma das instituições de saúde da G randeF I orianópol is, Santa Catarina. Para manter o anonimato, os recortes das falas dos participantes serão identificados, ao longo do texto, com a letra U (de usuário), seguida de um número de ordem $(1,2,3 \ldots)$.

Os encontros foram gravados e transcritos após autorização e assinatura do Termo de Consentimento Livre e E sclarecido. Em cada encontro, apresentou-se aos participantes os seis prin- cípios da Carta dos Direitos dos U suários do SU S, para que a discutissem e comparassem com 0 atendimento que Ihes era prestado.

Para o tratamento dos dados foi utilizada a A nálise Temática, na qual a fala dos participantes foi situada em seu contexto real e concreto; processo que compreende a ordenação, classificação e categorização final dos dados ${ }^{(9)}$.

Os aspectos éticos do estudo seguiram as recomendações da Resolução 196/ 96 do Conselho $\mathrm{N}$ acional de Saúde, que prescreve a ética na pesquisa com seres humanos no Brasil(10), com aprovação pelo Comitê de Ética em Pesquisa em Seres H umanos da U niversidade Federal de Santa Catarina (U F SC) sob número 074/ 2007.

\section{RESULTADOS E DISCUSSÃO DOS DADOS}

A pós a codificação dos dados foram categorizados os seguintes eixos temáticos: Direitos e deveres dos usuários; Qualificação profissional; A colhimento em saúde.

\section{Direitos e deveres dos usuários}

0 eixo Direitos e deveres dos usuários pode ser exemplificado com as seguintes fal as dos participantes:

0 usuário, hoje em dia, ele sabe que tem direito [ ...] . $M$ as, me diga se algum dia já leram. E ntão sabem os direitos, mas não sabem os deveres (U 2 e U 3).

0 usuário deveria seorientar mais. E ledeveria ir além. Seeu falar da palavra direito, eu tenho que saber o que éa palavra direito. T er direito, uma palavra muito linda. M as que direito? D ireito de que? 0 brasileiro sabe quetem direito, mas não sabenada do direito dele [ ...] . Você tem que saber o que vai reivindicar. N ão basta saber é preciso entender, discutir. [ ...] se mais gente fiz esse este trabalho que vocês estão faz endo, os usuários seriam mais inteligentes. Saberiam dizer o que é direito deles (U 5).

Diante desta discussão resgatou-se o primeiro princípio da carta o qual reforça o caráter univer sal do SU S como um sistema de saúde dirigido a todos os brasileiros. Assegura ao cidadão 0 acesso ordenado e organizado aos sistemas de saúde, visando a um atendimento mais justo e eficaz. T odos os cidadãos têm direito ao acesso às ações e aos serviços de promoção, proteção e recuperação da saúde promovidos pelo SU $S^{(3)}$. 
A discussão dos direitos à saúde pode estar relacionada ao crescente desenvolvimento tecnocientífico que vem tor nando o acesso à saúde cada vez mais excludente. Há uma visível diferença nos serviços prestados pelas instituições privadas e públicas. Enquanto nas primeiras 0 acesso é garantido mediante a lógica de mercado, do seguro privado, nas públicas percebe-se a não resolutividade e fragmentação da atenção nos difer entes níveis. A saúde passou a obedecer à lógica do mercado pelo poder econômico do complexo médicohospitalar e dos medicamentos, deixando de lado qualquer finalidade mais humana, ética e solidária ${ }^{(11)}$.

O utras discussões convergiram para a temática dos direitos e deveres dos cidadãos ganhando espaço já no ensino básico. No entender dos usuários essas questões devem ser problematizadas ampla e precocemente, para que o ser humano evolua como um ser crítico e co-responsável socialmente.

0 povo brasileiro já deveria vir da escola sabendo os seus direitos [ ...] para atingir amplamente os objetivos. M as o direito discutido e debatido! A criança sabe quetem o direito deir à escola. E letem queir a escola. M as por que el e tem que ir a escola? Os pais precisam questionar com a criança por que ela tem estedireito. É um meio para questionar, já começar na escola. É preciso questionar o porquê você tem este direi to e qual 0 seu dever. $\mathrm{N}$ ão faz er as coisas mecanicamente, é preciso começar na criança (U 5).

Compreender a complexidade dos processos de institucional ização dos direitos e deveres envolve a democratização das infor mações, dos julgamentos e tomadas de decisões. Envolve a consciência de que um povo saudável e educado se torna livre, soberano e capaz de decidir seu próprio futuro. É preciso conferir materialidade àquilo que pensamos, onde o real se constitui no lugar do exercício do imperativo ético do qual não podemos, como autores e atores sociais, nos furtar. É preciso afirmar a saúde como valor e responsabilidade, vínculo e resolução dos problemas, dir eitos e deveres ${ }^{(12)}$.

0 pleno estado de direito remete à promoção da saúde como fortalecimento da capacidade dos indivíduos e das comunidades para que analisem, aval iem e atuem junto aos deter minantes das suas condições de vida e saúde. Para isso, é preciso que os profissionais de saúde desenvolvam relações com os usuários e entre si, estabelecendo vínculos que respaldem e apóiem a assistência técnica prestada por eles. Isto também significa empoderar, não no sentido de dar poder a alguém, mas sim o ganho de poder por alguém. Poder para tomar decisões, para realizar ações, individuais e coletivas, implicando em auto-estima, motivação, consciência e compromisso social|(13).

D essa for ma, "ações que pretendam al cançar o 'empoderamento' dos grupos sociais - sujeitos das ações dos serviços de saúde - implicam na negação do assistencialismo como prática centrada em si mesma. Seu oposto são ações que valorizam a participação e a inclusão como estratégias"(13).

\section{Qualificação profissional}

A qualificação dos profissionais da saúde foi questionada, pelos usuários, em vários momentos:

Como estão sendo avaliados os profissionais da saúde? Quem os avalia? Por que em alguns locais eles atendem bem e em outros não? [ ...] ] á que vocês deram 0 nome de pesquisa, que no geral se avaliasse melhor os profissionais da saúde. Tem muitos profissionais aí que estão ganhando, mas não estão exercendo a profissão (U4).

M uitos profissionais não te dizem nem bom dia. [ ...] ficam presos nas suas planilhas (U 10$)$.

A (des)qualificação profissional foi uma queixa quase unânime dos usuários, como se estivessem demonstrando certo descaso em relação aos serviços públicos. E ste descaso é expresso pel o vaie-vem de infor mações e desinformações acerca do aonde o usuário deve ir e a quem procurar, que papéis levar, para quem levar, quanto tempo de espera, o porquê da demora para exames e consultas especializados, dentre outros relatos.

D estaca-se, aqui, o segundo princípio da cartilha: Todo cidadão tem direito a tratamento adequado e efetivo para seu problema. É direito dos cidadãos terem atendimento resolutivo com qualidade, em função da natureza do agravo, com garantia de continuidade da atenção, sempre que necessário(3,4).

Está clara na concepção dos usuários, que a saúde não pode continuar sendo tratada de forma irresponsável e desqualificada. 0 dir eito constitucional a saúde com qualidade e resolutividade não prescinde de princípios como cidadania e dignidade. 0 direito constitucional a saúde prescinde de 
políticas de saúde e discussões sobre o papel do estado, a relação estado-sociedade, as reações às condições de saúde da população e seus deter minantes, por meio de propostas e prioridades para a ação pública( ${ }^{(14)}$. A saúde é uma conquista, al cançada mediante a participação responsável e comprometida de todos os atores sociais.

0 dir eito dos cidadãos de terem atendimento resolutivo e com qualidade depende dos trabal hadores, ou seja, de atitudes profissionais responsáveis, ousadas, criativas, inovadoras, mas também, de gestão responsável, de vontade política e de políticas de saúde que garantam a justa destinação dos recursos para o SU S. Sem esquecer-se da participação ativa e crítica da sociedade nas discussões e decisões que delineiam ou determinam as prioridades de saúde de um país.

Sob outro prisma, a qualificação de profissionais da saúde está rel acionada e dependente do processo ensino-aprendizagem desenvolvido no âmago das universidades, que exercem um papel social de importância ímpar, influenciando transformações no sistema social, político, econômico e cultural da sociedade. Assim, torna-se imprescindível que os cursos univer sitários prepararem profissionais tecnicamente capazes de cumprir os desafios da modernidade e atender às demandas sociais e de saúde da população, possibilitando uma assistência humanizada e de acolhimento(15).

\section{Acolhimento em saúde}

Expressada dessa forma pelos participantes:

E u sou usuário e quero que me trate bem (U 3).

0 usuário deveria se orientar mais, ir além. 0 profissi onal, geralmente, não dá detalhes do seu probl ema de saúde T á ferindo o meu direito porque ele não me dá condições de saber qual éa minha verdadeira situação. $\mathrm{N}$ isso, o que pode ocor rer? Coisas muito mais sérias no futuro. Às vezes tem cuidados básicos que você pode começar ali, a partir daquela consulta e [...] poderia tratar e evitar complicações, atécom a própria alimentação (U 5).

Percebe-se a partir da fala dos usuários, que o diálogo estabel ecido entre profissionais da saúde e usuários é constitutivo do acolhimento e do estabelecimento do vínculo, que propicia a produção de ações de saúde de forma autônoma, responsabilizada e comprometida permitindo com que os usuários se organizem como sujeitos ativos do cuidado da sua saúde.

0 acolhimento remete ao terceiro princípio: Todo cidadão tem direito ao atendimento humanizado, acolhedor e livre de qual quer discriminação. É direito dos cidadãos o atendimento acolhedor na rede de serviços de saúde de forma humanizada, livre de qualquer discriminação, restrição ou negação em função de idade, raça, cor, etnia, orientação sexual, identidade de gênero, características genéticas, condições econômicas ou sociais, estado de saúde, ser portador de patologia ou pessoa vivendo com deficiência.

A ssim como a falta de interesse e a carência de uma atitude de escuta por parte dos profissionais, remete ao quarto princípio: T odo cidadão tem direito a atendimento que respeite a sua pessoa, seus valores e seus direitos. 0 respeito à cidadania por meio do Sistema de Saúde deve ainda observar, além de outros, os direitos de acesso aos mecanismos de escuta para apresentar sugestões, reclamações e denúncias aos gestores e às gerências das unidades prestadoras de ser viços de saúde e às ouvidorias, sendo respeitada a privacidade, o sigilo e a confidencialidade ${ }^{(3)}$.

0 acolhimento constitui-se, nessa perspectiva, num processo de responsabilização, escuta, atenção, vínculo e trabalho em equipe no sentido de estimular o respeito a autonomia do usuário e fazer com que este vença os obstáculos e desperte para o processo de auto-organização. A colher não significa atender a todos, mas abrir as portas do Sistema ao usuário de forma a recolocá-lo no local mais adequado para 0 atendimento de suas necessidades e demandas ${ }^{(16)}$

E u acho que é saber acolher, você saber passar segurança. A ssim, eu sei quando ela sai para um exame, ela foi fazer elá, quando eu cheguei, a minha filha não estava, si mplesmente levaram e não me avisaram. Você ficar sem saber o que ta acontecendo é complicado. Lá eu me senti totalmente desamparada, sozinha (U6).

0 acolhimento vai muito além do atendimento de qualidade, implica em atitudes humanas e relacionais que transmitam confiança e segurança. $\mathrm{N}$ esse sentido, 0 aparato tecnológico nem sempre é sinônimo de melhor assistência. Parece que a tecnologia ao invés de aproximar, tem se colocado como uma barreira que afasta os seres humanos cuidadores daqueles que são cuidados $^{(17)}$. 
Para garantir o direito ao atendimento acoIhedor e com qual idade, se faz necessário o investimento em qualificação dos profissionais. Os profissionais formam uma terceira ponta no sistema de saúde, com aproximação ao sistema educacional, responsável pela formação de profissionais e aos próprios gestores que devem permitir e favorecer a continuidade dessa formação através de investimentos em educação permanente ${ }^{(18)}$.

Para os participantes, ter cidadania e responsabilidade social implica em ser compreendido em sua individualidade e ser atendido em suas necessidades, como reflete a fala:

[ ...] a minha mãe foi fazer um preventivo e o cara do posto disse que ela tava com uma ferida no útero. [ ...] ela chorou, ficou apavorada. Veio aqui, fez todos os exames e não tinha nada! M as ela pensou que era um câncer! P orque não informaram direito pra ela? (U10).

O usuário, quando procura os serviços, busca a resolução de suas necessidades; não conseguindo, desloca-se de um serviço para outro até obter solução para seus problemas. A definição do problema leva em conta o conceito de saúde-doença apreendido por ele nas relações sociais e no cotidiano. Cabe aos trabalhadores/ gestores a compreensão e car acterização desses problemas a fim de tornar 0 atendimento mais acolhedor, utilizando uma abordagem que leve à solução competente e que satisfaça o usuário ${ }^{(16)}$.

A formação dos profissionais atuantes no SU S deverá levar em conta as propostas sugeridas de reconfiguração do modelo assistencial, buscando novas al ternativas de organização. A ssim, mediante o cenário de um mundo globalizado, prevalente em várias modalidades de desigual dades, é exigido da educação que interfira e faça sua parte. Os cursos da área da saúde, formando profissionais tecnicamente competentes, devem propiciar à população, uma assistência com qualidade, humanizada, de for ma responsável e ética(18). É preciso que as políticas públicas fundamentem-se em princípios que contemplem as reais necessidades dos usuários. N ão basta garantir 0 acesso e assegurar 0 atendimento prioritário para os casos mais críticos, mas assegurar a singularidade e o direito de cidadania de cada cidadão, independente do seu grau de risco e/ ou condição social.

As questões relacionadas à cidadania e aos direitos (e deveres) dos usuários da saúde preci- sam ser trabalhadas para despertá-los para a necessidade de participação popular nos assuntos de inter esse coletivo, tais como a saúde e, também, para que nossa atuação não seja restrita aos procedimentos técnicos, mas acompanhada de atitudes reflexivas e éticas. Isto porque, uma pessoa ao não ter clareza sobre seus direitos, pode vir a ter limitações no exercício de sua cidadania, as quais podem reduzir o nível de qualidade de vida(19).

A fala seguinte demonstra que os direitos se fazem acompanhar de deveres:

Se todos tivessem esse mesmo pensamento de buscar, exigir os seus direitos, eu acho que não seria como é [ ...] . É um direito garantido pelo governo federal, todos nós temos esse direito [ .... . T emos nossos deveres, no cumprimento de pagar os impostos pra fazer com que a nossa saúde trabalhe melhor, para que nosso governo trabalhe melhor, mas também temos os nossos direitos (U 7).

E ssa fala remete às inquietações e al guns paradoxos como: insatisfação de usuários, trabal hadores e gestores; baixo impacto sobre a saúde da população; avanço na garantia dos direitos e deveres assegurados na lei orgânica da saúde, mas, no cotidiano, na prática, sem ter os princípios do SU S garantidos.

0 país precisa retomar a efetivação do SU S constitucional que preconiza a saúde como direito de todos e dever do Estado, com comando único em cada esfer a de gover no, com participação e controle social. E fetivar um sistema público de fato, na prática cotidiana dos ser viços de saúde requer manter uma pactuação compartilhada entre gestores, profissionais da saúde e usuários, com inserção das universidades, sociedade civil organizada e das lideranças políticas, no sentido de garantir 0 financiamento da saúde, primar pelo compromisso de gestão solidária, ética e resolutiva, voltada para a mel horia da qual idade de vida, para um viver saudável da população brasileira.

\section{CONSIDERAÇÕES FINAIS}

O Sistema Ú nico de Saúde brasileiro, da forma como foi concebido, deveria e poderia ser um exemplo para o mundo inteiro. Exemplo, por ser um sistema único, organizado, integ rado e qual ificado, que busca garantir, por meio da participação popular e governamental, a preservação e a recuperação da saúde de todos os brasileiros. 
A pesar das grandes e importantes iniciativas e avançoS do SU S, percebe-se, no entanto, que ainda há muitos e importantes problemas que precisam tomar partido em nossos processos de reflexão e pesquisa. Problemas relacionados à qual idade do atendimento, filas de espera, falta de acesso, (des)compromisso por parte dos profissionais e gestores, desqualificação profissional, dentre outros, que são notícias cotidianas.

O SU S necessita, al ém de uma gestão responsável e boa vontade política, a participação efetiva dos usuários nas discussões e decisões vol tadas para o encaminhamento resolutivo das ações em saúde. Significa dizer, em outras palavras, que os cuidados com a saúde precisam de planejamento, participação e avaliação contínua para seus melhores resultados. É preciso entender que os cuidados em saúde são muito mais efetivos quando contemplam práticas integ radas e integ radoras aos saberes dos diferentes atores sociais.

O sistema de saúde de um país é, em suma, a conquista de uma sociedade que se empenha no exercício da cidadania. D e uma sociedade que participa por meio de seus direitos e deveres. De uma população que age como uma nação, verdadeiramente mobilizada em busca de mel hor es condições de vida. E nfim, de uma população que reflete, descobre e reivindica o que já é seu - SU S como precioso el emento integrante da sua vida.

\section{REFERÊNCIAS}

1 M inistério da Saúde (BR), Programa Nacional de H umanização da A tenção e G estão no Sistema Ú nico de Saúde. H umaniza SU S [ Internet] . Brasília (DF ); 2003 [ citado 2008 jun 27]. Disponível em: http:// portal.saude.gov.br/ portal/ saude/ cidadao/ area.cfm? id_area $=1342$.

2 M inistério da Saúde (BR). Política de Humanização da A ssistência à Saúde - PHA S [ Internet] . Brasília (DF); 2003 [ citado 2008 jun 27]. Disponível em: http:// portal.saude.gov.br/ saude/ area.cfm?id_ area $=390$.

3 M inistério da Saúde (BR ). Carta dos direitos dos usuários da saúde [ I nternet] . Brasília (D F ); 2006 [ citado 2008 jun 27] . Disponível em: http:/ / 189.28.128. 100/ portal/ arquivos/ pdf/ cartilha_ilustrada_ direitos_ 2006.pdf.

4 M inistério da Saúde (BR ). Portaria 399, de 22 de fevereiro de 2006: divulga o pacto pela saúde - 2006
Consolidação do SU S e aprova as diretrizes operacionais do referido pacto [ Internet] . Brasília (DF); 2006 [ citado 2008 jun 27]. Disponível em: http:/ / bvsms. saude.gov.br/ bvs/ saudel egis/gm/2006/ prt0399_22_02_2006.html.

5 Beck CLC, G onzales R M B, D enardin JM , T rindade $L L$, $L$ autert $L$. A humanização na per spectiva dos trabal hadores de enfer magem. T exto Contexto Enferm [ Internet] . 2007 [ citado 2009 maio 18];16(3):50310. D isponível em: http:/ / www.scielo.br/ sciel o.php? script $=$ sci_arttext $\&$ pid $=$ S0104-07072007000300017 $\& \operatorname{lng}=$ pt.

6 T hiollent M . M etodologia da pesquisa-ação. $2^{\text {a }}$ ed. São Paulo: Cortez; 1986.

7 Haguette T M F. M etodologias qualitativas na sociologia. 9ạ ed. Petrópolis: Vozes; 2003.

8 Cunha PV. M etodologia da pesquisa-ação [ Internet] . [ S.n.] : W ikispaces; 1986 [ citado 2008 jul 12] . Disponível em: http:/ / pesquisa-acao.wikispaces.com.

9 M inayo M CS. 0 desafio do conhecimento: pesquisa qual itativa em saúde. $8^{a}$ ed. São Paul o: H ucitec-A brasc0; 2004.

10 M inistério da Saúde (BR ), Consel ho N acional de Saúde. Resolução 196, de 10 de outubro de 1996: diretrizes e normas regulamentadoras de pesquisa envolvendo seres humanos. Brasília (DF ); 1996.

11 Lucchese PT R. E qüidade na gestão descentral izada do SU S: desafios para a redução de desigual dades em saúde. Ciênc Saúde Colet. 2003;8(2):439-48.

12 Pinheiro Junior RS, M atos RA. A tenção básica e integralidade: contribuições para estudos de práticas avaliativas em saúde. Rio de Janeiro: A brasco; 2008.

13 N ogueira-M artins M CF, Bógus CM . Considerações sobre a metodologia qual itativa como recurso para o estudo das ações de humanização em saúde. Saúde Soc [ Internet] . 2004 [ citado 2009 maio 18] ;13(3): 44-57. Disponível em: http:// www.scielo.br/ pdf/ sausoc/ v13n3/ 06.pdf.

14 Paim JS, T eixeira CF. Política, planejamento e gestão em saúde: balanço do estado da arte. Rev Saúde Pública [ I nternet] . 2006 [ citado 2009 abr 27]; 40 (n esp):73-8. D isponível em: http:/ / www.scielosp.org/ pdf/ rsp/ v40nspe/ 30625.pdf.

150 pitz SP, M artins JT, T elles F ilho PCP, Silva AE BC, T eixeira T CA . $O$ currículo integ rado na graduação em enfermagem: entre o ethos tradicional eo deruptura. Rev G aúcha E nferm [ I nter net] . 2008 [ citado 
2008 jun 28];29(2):314-9. Disponível em: http:/ / www.seer.ufr gs.br/ index.php/ R evistaG auchade Enfer magem/article/ view/ 5598/ 3207.

$16 \mathrm{M}$ arques $\mathrm{G}$, L eal S, Lima M , B onilha A, L opes $M$. Practices and daily routine of professionals in health public services under the light of academic studies. Online Braz J Nurs [ Internet]. 2006 [ cited 2009 M ar 07] ;6(2). Available from: http:/ / www. objnurs ing.uff.br/ index.php/ nursing/ article/ view/ 660.
$17 \mathrm{G}$ alimberti U . A emergência tecnológica ea passagem da cosmo-polis para a tecno-polis. Roma: Feltrinelli; 1999.

18 Pessini L, Pereira LL, Zaher VL, Silva M JP. Humanização em saúde: o resgate do ser com competência científica. M undo Saúde. 2003;27(2):203-5.

19 M artin L M . A ética ea humanização hospital ar. M undo Saúde. 2003;27(2):206-12.

\section{E ndereço da autora / Dirección del autor / Author's address:}

$M$ agda Santos Koerich

Rua D ona L eopoldina, 40, Ponta de Baixo

88104-022, São José, SC

E-mail: mskoerich@ccs.ufsc.br
Recebido em: 18/ 05/ 2009

A provado em: 21/ 12/ 2009 